\title{
Comparative cytogenetics in the genus Hoplias (Characiformes, Erythrinidae) highlights contrasting karyotype evolution among congeneric species
}

\author{
Ezequiel Aguiar de Oliveira ${ }^{1,2}$, Luiz Antônio Carlos Bertollo ${ }^{1}$, Cassia Fernanda Yano ${ }^{1}$, Thomas Liehr ${ }^{3}$
} and Marcelo de Bello Cioffi ${ }^{*}$

\begin{abstract}
Background: The Erythrinidae fish family contains three genera, Hoplias, Erythrinus and Hoplerythrinus widely distributed in Neotropical region. Remarkably, species from this family are characterized by an extensive karyotype diversity, with $2 n$ ranging from 39 to 54 chromosomes and the occurrence of single and/or multiple sex chromosome systems in some species. However, inside the Hoplias genus, while H. malabaricus was subject of many studies, the cytogenetics of other congeneric species remains poorly explored. In this study, we have investigated chromosomal characteristics of four Hoplias species, namely H. lacerdae, H. brasiliensis, H. intermedius and H. aimara. We used conventional staining techniques (C-banding, Ag-impregnation and $\mathrm{CMA}_{3}$-fluorescence) as well as fluorescence in situ hybridization (FISH) with minor and major rDNA and microsatellite DNAs as probes in order to analyze the karyotype evolution within the genus.
\end{abstract}

Results: All species showed invariably $2 n=50$ chromosomes and practically identical karyotypes dominated only by meta- and submetacentric chromosomes, the absence of heteromorphic sex chromosomes, similar pattern of C-positive heterochromatin blocks and homologous Ag-NOR-bearing pairs. The cytogenetic mapping of five repetitive DNA sequences revealed some particular interspecific differences between them. However, the examined chromosomal characteristics indicate that their speciation was not associated with major changes in their karyotypes.

Conclusion: Such conserved karyotypes contrasts with the extensive karyotype diversity that has been observed in other Erythrinidae species, particularly in the congeneric species H. malabaricus. Nevertheless, what forces drive such particularly different modes of karyotype evolution among closely related species? Different life styles, population structure and inner chromosomal characteristics related to similar cases in other vertebrate groups can also account for the contrasting modes of karyotype evolution in Hoplias genus.

Keywords: Trahiras, Fish cytogenetics, FISH, Repetitive DNA, Chromosome change and speciation

\section{Background}

Erythrinidae is a small family of freshwater fishes composed by three genera, Hoplias Gill 1903, Erythrinus Scopoli 1777 and Hoplerythrinus Gill 1895 [1]. Its species are characterized by a remarkable karyotype diversity with $2 \mathrm{n}$ ranging from 39 to 54 chromosomes and the occurrence of single and multiple sex chromosome systems in some species.

\footnotetext{
* Correspondence: mbcioffi@ufscar.br

'Universidade Federal de São Carlos, Departamento de Genética e Evolução, São Carlos, SP, Brazil

Full list of author information is available at the end of the article
}

Thus, they represent an interesting and suitable model to investigate the process of chromosomal evolution among fishes [2-5].

Although small, the actual diversity, systematics and corresponding taxonomic construction of Erythrinidae is still not well resolved. Especially in the Hoplias genus, three major groups of species were identified based on their morphological characters: $H$. lacerdae, $H$. malabaricus and $H$. macrophtalmus [6]. The lacerdae group was recently revised and 5 valid species are now recognized namely H. lacerdae, H. intermedius, H. brasiliensis, H. curupira and 
$H$. australis, the last two being newly described ones [6]. Species of macrophthalmus group have also been revised and only $H$. aimara is now recognized [7]. In turn, the malabaricus group still requires a taxonomic revision [3].

In fact, the overall cytogenetic data suggest that $H$. malabaricus presents an extensive karyotype variation characterized by 07 major karyomorphs easily distinguishable from each other [2, 3]. In addition, different classes of repetitive DNAs also provided relevant data about population diversification, demonstrating that they are good chromosomal markers to detect recent evolutionary events (reviewed in [4]).

Excluding $H$. malabaricus, little cytogenetic information is available for other Hoplias species. Some previous data points towards one similar karyotype, with an invariable $2 n=50$ and the absence of differentiated sex chromosomes [8-10]. Thus, such conserved karyotypes contrast with the extensive chromosome diversity that has been observed in other Erythrinidae species, and particularly among the representatives of the $H$. malabaricus group.

Therefore, this study aimed to complete cytogenetic data for another rather neglected Hoplias species using conventional and molecular cytogenetic methods. It was aimed to (1) enhance the knowledge of the karyotype structure of these species (2) investigate the chromosomal relationships among them and (3) highlight the contrasting evolutionary pathways inside Hoplias genus.

\section{Results}

All species under study had invariably $2 n=50$ chromosomes in both sexes, showing only minor variations in their karyotypes. They possessed $20 \mathrm{~m}$ and $30 \mathrm{sm}$ chromosomes in $H$. intermedius, $H$. brasiliensis and $H$. aimara, while $16 \mathrm{~m}$ and $34 \mathrm{sm}$ chromosomes were found in H. lacerdae. Additionally, 1-2 B-chromosomes were presented in some H. aimara individuals (Figs. 1 and 2). Blocks of C-positive heterochromatin were observed in the centromeric region of all chromosomes and in the terminal region of some chromosome pairs (Figs. 1 and 2).

However, CDD ( $\left.\mathrm{CMA}_{3} / \mathrm{DAPI}\right)$ staining revealed significant variation of the fluorescent chromosomal pattern among species. While $H$. intermedius and $H$. brasiliensis showed eight $\mathrm{CMA}_{3}^{+}$sites at the centromeric regions of four chromosome pairs, $H$. aimara showed only 2 sites in one sm chromosome pair, also present in the two former species (Figs. 1 and 2). Contrary, $H$. lacerdae, did not present any $\mathrm{CMA}_{3}^{+}$sites on their chromosomes (Fig. 2).

The chromosomal mapping using microsatellite DNAs $(\mathrm{GA})_{15}$ and $(\mathrm{CA})_{15}$ showed similar patterns in the examined species, with scattered signals and a remarkable accumulation in the subtelomeric regions of all chromosomes. However, different patterns were observed among species after FISH with the microsatellite $(\mathrm{CAA})_{10}$. Besides the presence of scattered signals, a considerable accumulation of this sequence was detected in a non-homologous chromosome pair among species; with the exception of $H$. lacerdae where such accumulation was not verified (Figs. 3, 4, 5 and 6).

All species possessed only one, likely interspecifically homologous chromosome pair bearing 5S rDNA sites. Differently, the $18 \mathrm{~S}$ rDNA sites showed species-specific pattern, representing a good cytotaxonomic marker. All species shared one homologous sm chromosome pair bearing $18 \mathrm{~S}$ rDNA sites, corresponding also to silverpositive, active Ag-NORs. In addition, H. brasiliensis, $H$. aimara and $H$. lacerdae had four, two and one additional $18 \mathrm{~S}$ rDNA sites, respectively, some of them homologous among these species (Figs. 3, 4, 5 and 6).

Figure 7 graphically depict the results of conventional and molecular cytogenetic analyses.

\section{Conclusions}

\section{Insights into the karyotype evolution in Hoplias}

Apart from some minor characteristics, such as a slightly different number of $\mathrm{m}$ and sm chromosomes in $\mathrm{H}$. lacerdae and the presence of some B-chromosomes in $H$. aimara, the four species showed a high similarity in their karyotypes. In addition, no heteromorphic sex chromosomes were detected and a similar pattern of C-positive heterochromatin was also observed. Therefore, the speciation process in $H$. lacerdae, $H$. brasiliensis, $H$. intermedius and $H$. aimara was not accompanied by significant changes at the chromosomal level. Such conservative pattern is also supported by some previous results, where different populations of $H$. aimara and $H$. intermedius [10], and undetermined individuals of the so called "lacerdae group" [9], shared the same karyotypes.

However, even though obvious major changes in the karyotypes of these Hoplias species were not observed, the cytogenetic mapping of different repetitive DNA sequences provided reliable chromosomal markers, revealing some species-specific differences, as also reported for other different populations of $H$. aimara and $H$. intermedius [10]. In fact, repetitive DNAs are highly dynamic throughout evolution and, therefore, their application in evolutionary studies provides significant contributions $[11,12]$. Although the $5 \mathrm{~S}$ rDNA sites showed an identical position in the chromosomes of the four species, the distribution of the $18 \mathrm{~S}$ rDNA and corresponding $\mathrm{CMA}_{3}^{+}$sites had different patterns. With the exception of $H$. lacerdae, all other species shared a likely identical sm chromosome pair bearing $18 \mathrm{~S} \mathrm{rDNA} / \mathrm{CMA}_{3}^{+}$sites, which were also the only active Ag-NOR sites (Figs. 1, 2, 3,4, 5, 6 and 7). In fact, the cytologically detectable correspondence of GC-rich DNA with major rDNA sites is evolutionary conserved for all Actinopterygii, except Acipenseriformes [13-17]. However, not all rDNA sites were necessarily GC-rich, a condition that has also been found in other fish species $[18,19]$. 


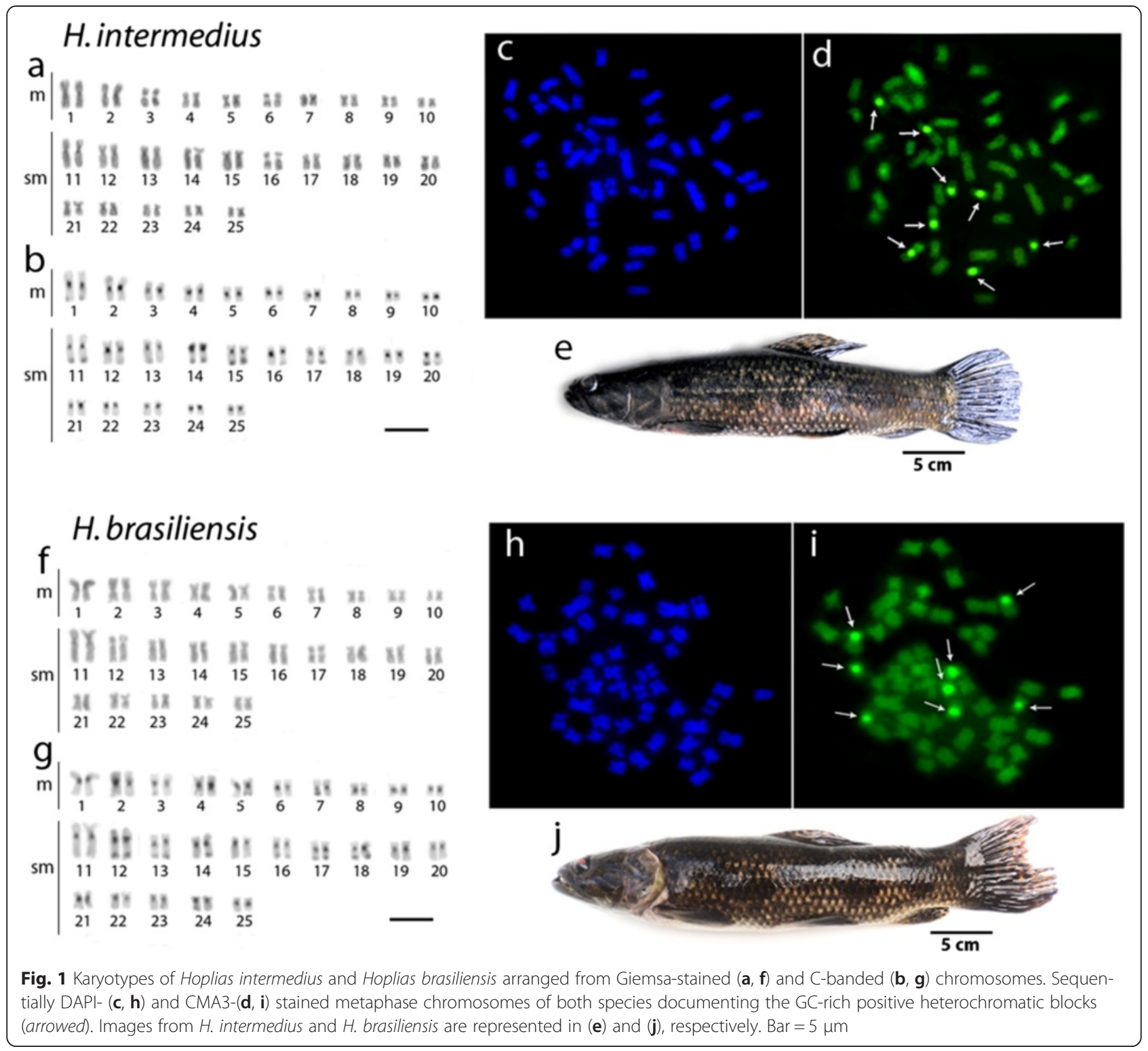

Additional 18S rDNA sites were found in the genome of $H$. brasiliensis, $H$. aimara and $H$. lacerdae, each species presenting a particular pattern of six, four and three sites, respectively. Notably, just one chromosome of the homologous pair displaying an rDNA site was observed in H. brasiliensis and H. lacerdae (Fig. 7). This pattern may be due to i) a limitation of the FISH technique in detecting the rDNA sequences in both chromosomes due to their reduced copy number; ii) the occurrence of unequal crossing overs changing the rDNA amount between homologues, iii) the simple deletion of this segment; iv) a polymorphic condition or v) the mobility of rDNA sequences by the activity of Transposable Elements (TEs). In fact, fish genomes contain many types of TEs and a number of studies have recently evidenced their potential to cause rDNA mobility [12, 20, 21]. Particularly, in another Erythrinidae species, $E$. erythrinus, the insertion of the retrotransposable element Rex3 into rDNA sequences is thought to be the main source of the rDNA spreading in the genome [22, 23].

Microsatellites are abundant repeated sequences present in all eukaryotes studied thus far and they are found either between the coding regions of structural genes or between other repetitive sequences [24]. In fish genomes, microsatellites are usually localized in the telomeres and centromeres, where a significant fraction of repetitive DNA is also present [25]. Microsatellites (CA) 15 and (GA) 15 showed a general similar distribution in the four species analyzed, being abundantly located in the subtelomeric regions of all chromosomes, as also observed in some other fish species such as Triportheus trifurcatus, Imparfinis schubarti, Danio rerio and in H. malabaricus [26-28]. In contrast, the microsatellite $(\mathrm{CAA})_{10}$ showed a specific 


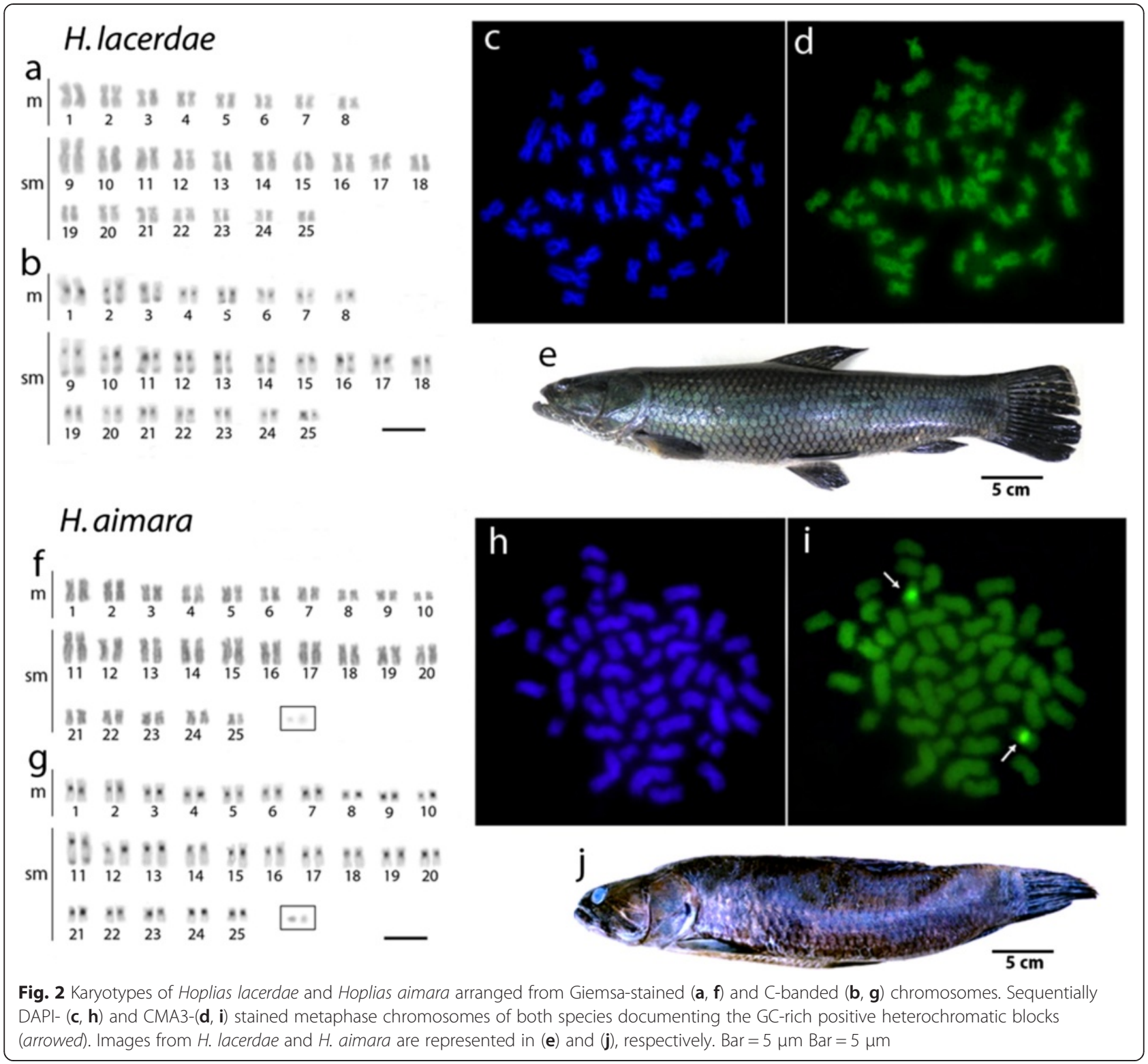

pattern for $H$. intermedius, $H$. brasiliensis and $H$. aimara. Indeed, besides its wide scattered distribution along chromosomes, a strong accumulation was found in a particular chromosome pair for each species, with exception for $H$. lacerdae, therefore displaying specific zones of accumulation and pointing out distinct evolutionary pathways concerning the genome organization among Hoplias species.

Indeed, repetitive DNAs are characterized by a dynamic evolutionary process $[29,30]$ and one of the main properties of microsatellite sequences is their capacity to originate variations with different numbers of repeats [31]. In this way, the repetitive fraction of the genome (as here exemplified by the rDNAs and microsatellites) seems to escape the selective pressure that acts in the non-repetitive segments, thus being able to show recent evolutionary events [32]. Therefore, although preserving a similar karyotype, some inner chromosomal differentiations can be found among species, probably due to a restricted gene flow, thus corroborating their recent taxonomic recognition.

However, the most intriguing feature emerges when we analyze the existing pattern in H. malabaricus (Fig. 8). Differently from the karyotypes composed by $2 \mathrm{n}=50 \mathrm{~m}$ and sm chromosomes conserved between sexes and species analyzed in the present study, $H$. malabaricus presents a remarkable differentiation between populations distributed throughout the Neotropics. For these populations, several karyomorphs are characterized, diverging in their 2n, karyotypes, distribution of repetitive DNA sequences and presence of simple or multiple sex 


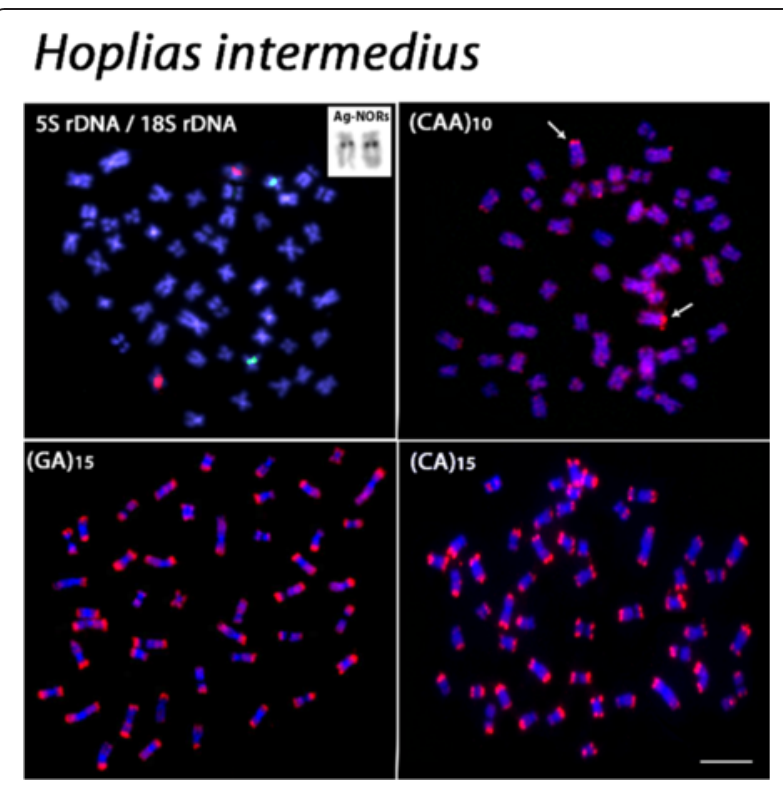

Fig. 3 Hoplias intermedius chromosomes showing the 18S rDNA (red) and $5 \mathrm{~S}$ rDNA (green) sites, the Ag-NOR bearing chromosome pair, and the distribution of $(\mathrm{CAA})_{10},(\mathrm{GA})_{15}$ and $(\mathrm{CA})_{15}$ microsatellites. Note the general distribution pattern of microsatellites and a more conspicuous (CAA) 10 site in the short arms of a submetacentric chromosome (arrows). Bar $=5 \mu \mathrm{m}$

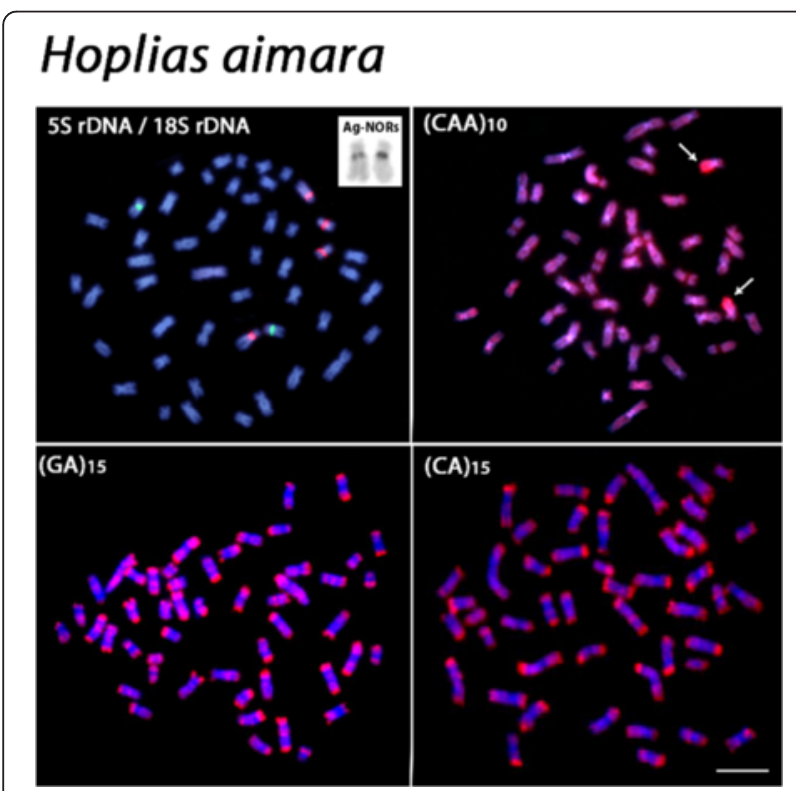

Fig. 4 Hoplias aimara chromosomes showing the 18S rDNA (red) and $5 \mathrm{~S}$ rDNA (green) sites, the Ag-NOR bearing chromosome pair, and the distribution of (CAA) ${ }_{10},(\mathrm{GA})_{15}$ and $(\mathrm{CA})_{15}$ microsatellites. Most conspicuous (CAA) 10 sites in the long arms of a submetacentric chromosome pair are indicated by arrows. Bar $=5 \mu \mathrm{m}$

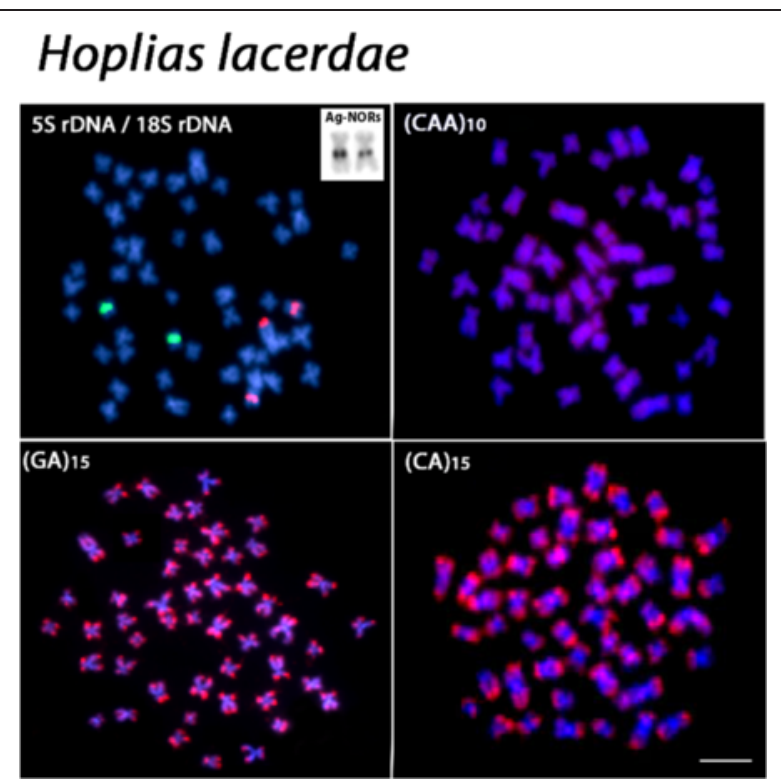

Fig. 5 Hoplias lacerdae chromosomes showing the 185 rDNA (red) and $5 \mathrm{~S}$ rDNA (green) sites, the Ag-NOR bearing chromosome pair and the distribution of $(C A A)_{10},(G A)_{15}$ and $(C A)_{15}$ microsatellites. Bar $=5 \mu \mathrm{m}$

chromosome systems [2-4, 33]. While some of these karyomorphs are endemic to a certain watersheds, other ones have a wide geographical distribution, being also found in sympatry without detection of hybrids [2]. In addition, molecular phylogenetic analyzes have also highlighted the evolutionary divergence within a same

\section{Hoplias brasiliensis}

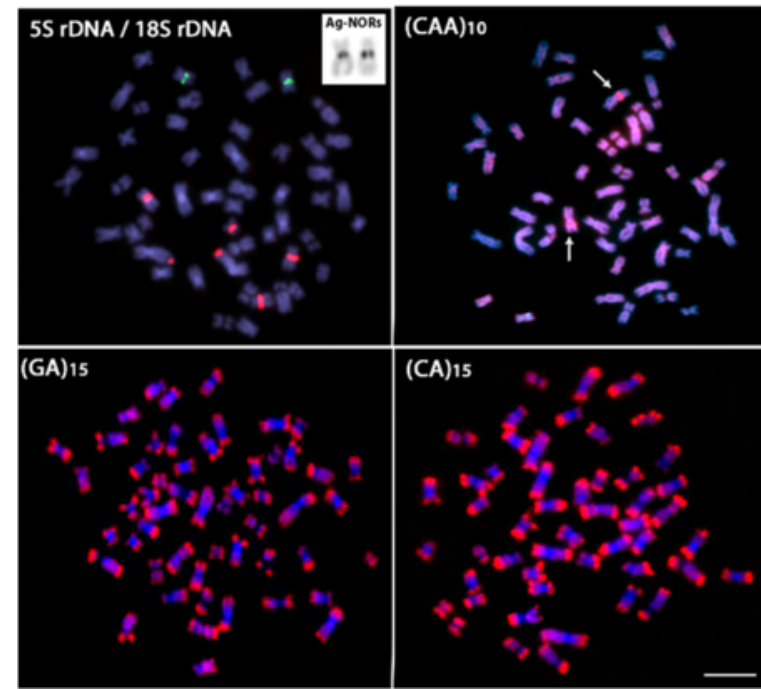

Fig. 6 Hoplias brasiliensis chromosomes showing the 18S rDNA (red) and 55 rDNA (green) sites, the Ag-NOR bearing chromosome pair, and the distribution of $(C A A)_{10},(G A)_{15}$ and $(C A)_{15}$ microsatellites. Most conspicuous $(C A A)_{10}$ sites in the proximal region of a metacentric chromosome pair are indicated by arrows. Bar $=5 \mu \mathrm{m}$ 


\begin{tabular}{|c|c|c|c|c|c|c|c|c|c|c|}
\hline Species & $2 n$ & Karyotype & $\mathrm{NF}$ & Ag-NORs & $18 \mathrm{~S}$ rDNA & $5 S \mathrm{rDNA}$ & $\mathrm{CMA}_{3}^{+}$ & $(G A)_{15}$ & $(C A)_{15}$ & $(\mathrm{CAA})_{10}$ \\
\hline H. intermedius & 50 & $20 m-30 s m$ & 100 & m. & & 80 & & & & \\
\hline H. brasiliensis & 50 & $20 m-30 s m$ & 100 & no. & & & & & & \\
\hline H. aimara & 50 & $\begin{array}{c}20 m-30 s m \\
+1-2 B s\end{array}$ & 100 & ¿.o. & & 80 & & & & \\
\hline H. lacerdae & 50 & $16 m-34 s m$ & 100 & ים" & & 双 & & & & \\
\hline
\end{tabular}

Fig. 7 Summary of the main chromosomal characteristics of the Hoplias species under study

karyomorph, thus supporting the hypothesis that it may contain more than one species [34]. Accordingly, differentiation between populations of a single major karyomorph has also been evidenced by the distribution of repetitive DNAs on chromosomes, revealing the actual systematic diversity present in this group [35].

Therefore, a general chromosomal conservatism found in the four Hoplias species analyzed contrasts with the extensive karyotype diversity that has been observed in other Erythrinidae species, notably in the congeneric species $H$. malabaricus.

What drives distinct modes of karyotype evolution among closed related species?

Karyotype diversification processes and morphological patterns are often indicators of the lifestyle of a species [36], and several vertebrates provide an opportunity to search for such correlations once some lineages have experienced faster rates of evolutionary changes in anatomy and in their way of life than others have [37].

In mammals, for example, some related taxa present distinct rates of chromosomal evolution and this might be explained by the way the species are socially organized [38]. It has been suggested that the social systems evolved by some mammalian groups produce population structures that enhance inbreeding and genetic drift, thereby facilitating the fixation of chromosomal rearrangements [39]. The key factor involved seems to be the type of social behavior, which produces small effective population sizes and inbreeding [40-43]. Interestingly, two modes of chromosomal evolution are present among salmonid fishes, which are either anadromous or found in specialized lacustrine environments. It was proposed that selection for increases or decreases in genetic recombination could have been involved in the evolution of chromosome number in these fishes, and if the rearrangements occur without a selective advantage, extensive changes would be

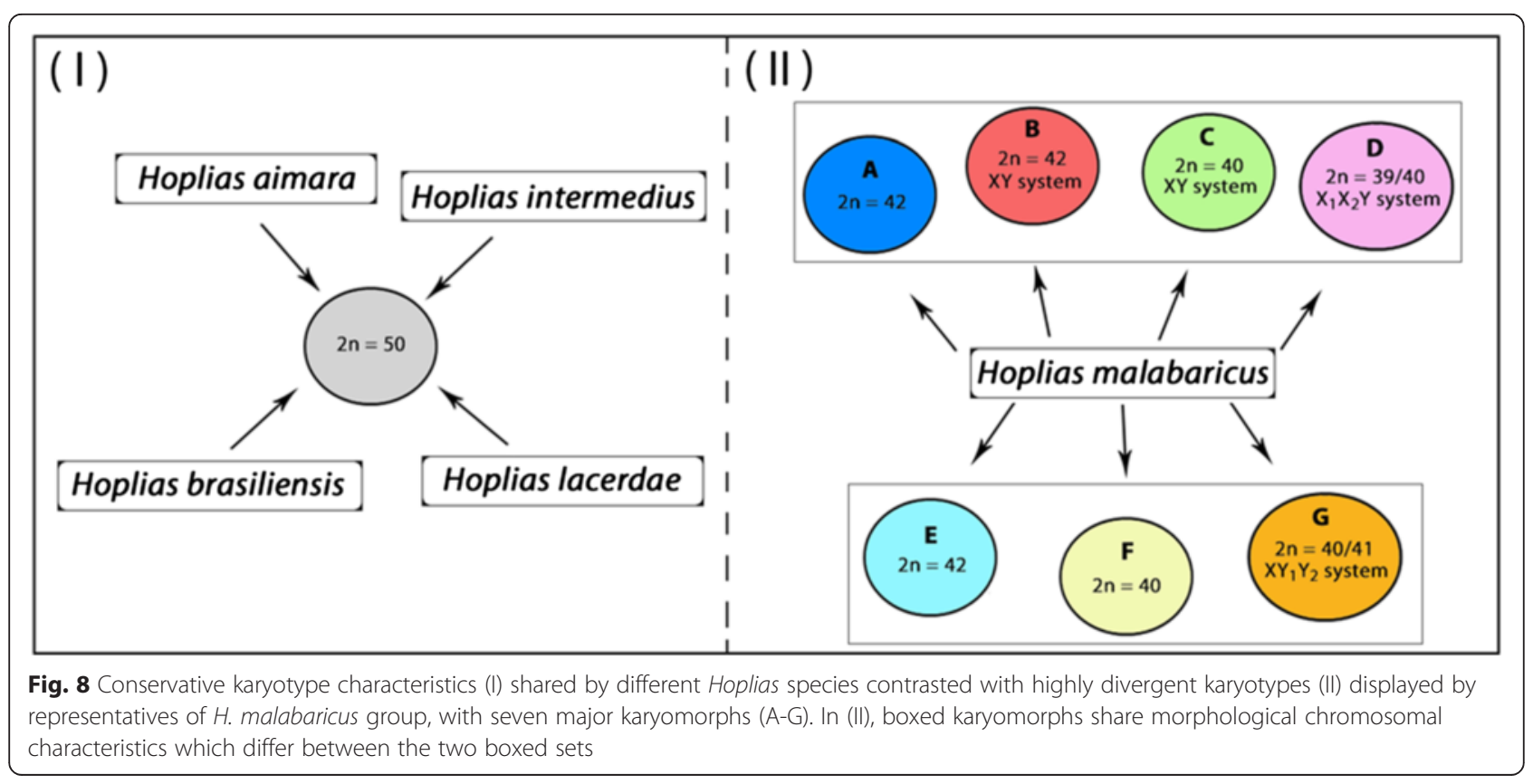


associated with small effective population sizes [44]. Similarly, in Hoplias species two main situations can be also occur concerning their ecological habits. While H. malabaricus is characterized by having a more sedentary habitat, inhabiting mainly marginal lakes; $H$. lacerdae, $H$. aimara, $H$. brasiliensis and $H$. intermedius occupy preferably the main channel of the rivers [10]. Therefore, smaller and more isolated populations can be commonly found in H. malabaricus, increasing the probability of fixation of chromosomal rearrangements and thus generating intraand inter karyotype diversity, unlike other Hoplias species. The different lifestyle models and population structure found within genus Hoplias can, therefore, be correlated with the highly differentiated chromosomal diversity among its congeneric species.

In fact, chromosomal rearrangements may spread to fixation in small populations where there is a higher probability in generating homozygous rearranged forms that are free of meiotic segregation problems [45]. The fact that many species differ by fixed and specific chromosome rearrangements, suggests that those ones that contribute to speciation are most likely to accumulate in allopatry or under restricted gene flow [46]. Indeed, fish species characterized by higher mobility and population density usually present few chromosome rearrangements, as exemplified by some migratory Neotropical fishes, such as Anostomidae, Prochilodontidae, Curimatidae, in which none or little changes are found in their karyotypes $[47,48]$. On the contrary, high karyotype variability is usually present in fish groups with low mobility and exhibiting small isolated populations. Such behaviors contributed, for example, to the large chromosome variation found among fishes of the genus Channa, in which the diploid number varies from $2 \mathrm{n}=32$ in C. punctata to $2 \mathrm{n}=112$ in $C$. gachua. In this case, Robertsonian rearrangements, pericentric inversions and polyploidy characterize different species/populations, appearing as the main sources of such chromosomal diversity [49-51].

Additionally, other features related to the own genomic organization may be also taken into account in generating chromosome variability, as well exemplified in Cricetidae mammals. In this family, two lemmings' genera, Lemmus and Dicrostonyx, have similar population structures, but while little chromosome variability is present in the former one, a higher rate is found in the later [52]. In fact, chromosome breakage in evolution is a nonrandom process, resulting in segments that are conserved over millions of years in contrast to other unstable regions that are more likely to be involved in rearrangements, because of their underlying sequence features [53]. Chromosome fragility has been also linked with the karyotype evolution of some other mammalian species, such as the rock wallabies of the Petrogale genus [54], primates of the Cebidae family [55] and deer species of Mazama genus [56]. Therefore, besides the different life styles, inner chromosomal characteristics may also account for the contrasting evolutionary models that occur in the Hoplias genus. However, some other approaches such as intrinsic molecular and meiotic features, and external issues like the effective population size, gene flow and population dynamics, will be useful tools for further clarifying this peculiar scenario.

\section{Methods}

\section{Material}

Chromosome preparations were obtained from four Hoplias species as specified in Table 1 . The samples were collected with the authorization of the Brazilian environmental agency ICMBIO/SISBIO (License number 486282). All species were properly identified by Prof. Dr. Oswaldo T. Oyakawa, being deposited in the Museum of Zoology of the University of São Paulo (MZUSP) (Table 1).

\section{Mitotic chromosome preparations}

The animals were first injected in the abdominal region with a $0.025 \%$ aqueous solution of colchicine at a dose of $1 \mathrm{ml} / 100 \mathrm{~g}$ of weight. After $50-60 \mathrm{~min}$, the specimens were anesthetized and sacrificed, and the chromosomal preparations were made from cells of the anterior kidney [8]. The procedures were performed in accordance with the Ethics Committee on Animal Experimentation of the Universidade Federal de São Carlos (Process number CEUA1853260315).

\section{Chromosome staining}

In addition to the conventional Giemsa method, chromosomes were analyzed after silver nitrate staining [57] in order to visualize the nucleolar organizing regions (Ag-NORs). C-banding was also employed to detect the C-positive heterochromatin [58] and Chromomycin A3

Table 1 Collection sites of Hoplias species, with the respective sample sizes and museum codes identification

\begin{tabular}{|c|c|c|c|}
\hline Species & Locality & Number & Museum deposit \\
\hline Hoplias brasiliensis & Grão Mogol (MG) - Itacambiruçú River (Jequitinhonha River Basin) & $08 \delta^{\lambda} 02+$ & EAO2014103101 \\
\hline Hoplias aimara & Querência (MT) - Xingu River (Amazon River Basin) & $030^{0} 019$ & EAO2014080302 \\
\hline Hoplias intermedius & Fish culture facility (Poço Fundo - MG) & $04{ }^{\lambda} 04$ & EAO2014082801 \\
\hline Hoplias lacerdae & Fish culture facility (Poço Fundo - MG) & $02 \widehat{\jmath} 060$ & EAO2014082802 \\
\hline
\end{tabular}


$\left(\mathrm{CMA}_{3}\right)$ staining to identify the GC-rich regions on the chromosomes [15].

\section{Fluorescence in situ hybridization (FISH)}

Two tandemly arrayed rDNA sequences isolated from the genome of $H$. malabaricus were used. The first probe contained a $5 \mathrm{~S}$ rDNA repeat copy and included $120 \mathrm{bp}$ of the $5 \mathrm{~S}$ rRNA transcribing gene and $200 \mathrm{bp}$ of the non transcribed spacer (NTS) [59]. The second probe corresponded to a 1400-bp segment of the 18S rRNA gene obtained via PCR from nuclear DNA [35]. The 18S rDNA probe was labeled with biotin-14-dATP using the kit Biotin-Nick Translation Mix (Roche), while the 5S rDNA probe was labeled with digoxigenin-11-dUTP, using the kit DIG-Nick Translation Mix (Roche), according to manufacturer's instructions. Additionally, oligonucleotide probes containing microsatellite sequences $(\mathrm{CA})_{15},(\mathrm{GA})_{15}$ and $(\mathrm{CAA})_{10}$, directly labeled with $\mathrm{Cy} 3$ during synthesis by Sigma (St. Louis, MO, USA) [60], were also applied.

\section{Slides preparation, hybridization and signal detection}

The FISH method was conducted as follows: slides with fixed chromosomes were maintained at $37^{\circ} \mathrm{C}$ for $1 \mathrm{~h}$. Subsequently, they were incubated with RNAse $(10 \mathrm{mg} / \mathrm{ml})$ for $1 \mathrm{~h}$ at $37{ }^{\circ} \mathrm{C}$ in a moist chamber. Next, it was performed a 5-min wash with $1 \mathrm{xPBS}$ and $0.005 \%$ pepsin was applied to the slides (10 min at room temperature). The slides were then washed again with 1 XPBS. The material was fixed with $1 \%$ formaldehyde at room temperature for $10 \mathrm{~min}$. After further washing, the slides were dehydrated with 70, 85 and $100 \%$ ethanol, 2 min in each bath. The chromosomal DNA was denatured in $70 \%$ formamide/ 2xSSC for $3 \mathrm{~min}$ at $72{ }^{\circ} \mathrm{C}$. The slides were dehydrated again in a cold ethanol series (70, 85 and $100 \%$ ), 5 min each. The hybridization mixture, containing $100 \mathrm{ng}$ of denatured probe, $10 \mathrm{mg} / \mathrm{ml}$ dextran sulfate, 2xSSC and $50 \%$ formamide (final volume of $30 \mu \mathrm{l}$ ) were heated to $95^{\circ} \mathrm{C}$ for $10 \mathrm{~min}$ and then applied on the slides. Hybridization was performed for a period of $16-18 \mathrm{~h}$ at $37{ }^{\circ} \mathrm{C}$ in a moist chamber. After hybridization, the slides were washed for 5 min with $2 x S S C$ and then rinsed quickly in 1xPBS. The detection of the probes was performed with StreptavidinCy3 (Sigma) for the 18S rDNA probe and anti-digoxigeninFITC (Roche) for the 5S rDNA probe. The chromosomes were counterstained with DAPI $(1.2 \mathrm{~g} / \mathrm{ml})$ in Antifading solution (Vector Laboratories).

\section{Microscopy analyses and image processing}

Approximately 30 metaphase spreads were analyzed to confirm the diploid chromosome number, karyotype structure and FISH results. Images were captured on an Olympus BX50 microscope (Olympus Corporation, Ishikawa, Japan) using CoolSNAP and the Image Pro Plus 4.1 software (Media Cybernetics, Silver Spring,
MD, USA). The chromosomes were classified as $\mathrm{m}$ or sm according to their arm ratios [61].

\begin{abstract}
Abbreviations
2n: diploid number; $\mathrm{CMA}_{3}$ : Chromomycin A3; DAPI: 4',6-diamidino-2phenylindole; dUTP: 2'-Deoxyuridine-5'-Triphosphate; FISH: Fluorescence in situ hybridization; M: Metacentric chromosome; NOR: Nucleolar organizing regions; PCR: Polymerase chain reaction; rDNA: ribosomal DNA; rRNA: ribosomal RNA; sm: submetacentric chromosome.
\end{abstract}

\section{Competing interests}

The authors declare that they have no competing interests.

\section{Authors' contributions}

$\mathrm{EAO}, \mathrm{CFY}$ and $\mathrm{MBC}$ carried out the molecular cytogenetic analysis and drafted the manuscript. EAO, CFY, MBC, LACB and TL helped in analysis and drafted the manuscript. MBC and $\angle A C B$ coordinated the study, drafted and revised the manuscript. All authors read and approved the final version of the manuscript.

\section{Acknowledgements}

The authors are grateful to Mr. José Salles Alvim Junior, from the "Aquaminas" fish culture, for providing some specimens for this research and to Dr. Oswaldo T. Oyakawa, from the Museu de Zoologia da Universidade de São Paulo (MZUSP) for the identification of the fish species. We are also grateful to the Secretaria de Estado de Educação de Mato Grosso - SEDUC-MT - for the license granted to E.A.O. to carry out his postgraduate studies. This work was supported by the Brazilian agencies FAPESP (Fundação de Amparo à Pesquisa do Estado de São Paulo), CNPq (Conselho Nacional de Desenvolvimento Científico e Tecnológico) and CAPES (Coordenação de Aperfeiçoamento de Pessoal de Nível Superior).

\section{Author details}

'Universidade Federal de São Carlos, Departamento de Genética e Evolução, São Carlos, SP, Brazil. ²SEDUC-MT, Cuiabá, MT, Brazil. J Jena University Hospital, Friedrich Schiller University, Institute of Human Genetics, Kollegiengasse 10, D-07743 Jena, Germany.

Received: 28 May 2015 Accepted: 14 July 2015

Published online: 30 July 2015

\section{References}

1. Oyakawa OT. Family Erythrinidae. In: Reis RE, Kullander SO, Ferraris Jr CJ, editors. Check list of the freshwater fishes of South and Central America. Porto Alegre: Edipucrs; 2003. p. 238-40.

2. Bertollo LAC, Born GG, Dergam JA, Fenocchio AS, Moreira-Filho O. A biodiversity approach in the Neotropical Erythrinidae fish, Hoplias malabaricus. Karyotypic survey, geographic distribution of cytotypes and citotaxonomic considerations. Chromosome Res. 2000;8:603-13.

3. Bertollo LAC. Chromosome evolution in the Neotropical Erythrinidae fish family: An overview. In: Pizano E, Ozouf-Costaz C, Foresti F, Kapoor BG, editors. Fish Cytogenetics. Enfield: Science Publishers; 2007. p. 195-211.

4. Cioffi MB, Molina WF, Artoni RF, Bertollo LAC. Chromosomes as tools for discovering biodiversity. The case of Erythrinidae fish family. In: Tirunilai P, editor. Recent Trends in Cytogenetic Studies. Methodologies and Applications. Rijeka: Intech; 2012. p. 125-46.

5. Cioffi MB, Liehr T, Trifonov $V$, Molina WF, Bertollo LAC. Independent sex chromosome evolution in lower vertebrates: A molecular cytogenetic overview in the Erythrinidae fish family. Cytogenet Genome Res. 2013;141:86-194.

6. Oyakawa OT, Mattox MT. Revision of the Neotropical trahiras of the Hoplias lacerdae species-group (Ostariophysi: Characiformes: Erythrinidae) with descriptions of two new species. Neotrop Ichthyol. 2009;7:117-40.

7. Mattox GT, Toledo-Piza M, Oyakawa OT. Taxonomic study of Hoplias aimara (Valenciennes, 1846) and Hoplias macrophthalmus (Pellegrin, 1907) (Ostariophysi, Characiformes, Erythrinidae). Copeia. 2006;2006(3):516-28.

8. Bertollo LAC, Takahashi CS, Moreira-Filho O. Cytotaxonomic considerations on Hoplias lacerdae (Pisces, Erythrinidae). Braz J Genet. 1978;1:103-20. 
9. Morelli S, Vicari MR, Bertollo LAC. Evolutionary cytogenetics of the Hoplias lacerdae, Miranda Ribeiro, 1908 group. A particular pathway concerning the other Erythrinidae fish. Braz J Biol. 2007;67:897-903.

10. Blanco DR, Lui RL, Vicari MR, Bertollo LAC, Moreira-Filho O. Comparative cytogenetics of giant trahiras Hoplias aimara and $\mathrm{H}$. intermedius (Characiformes, Erythrinidae): Chromosomal characteristics of minor and major ribosomal DNA and cross-species repetitive centromeric sequences mapping differ among morphologically identical karyotypes. Cytogenet Genome Res. 2011;132:71-8.

11. Biemont C, Vieira C. Genetics: junk DNA as an evolutionary force. Nature. 2006;443:521-4.

12. Raskina O, Barber JC, Nevo E, Belyayev A. Repetitive DNA and chromosomal rearrangements: Speciation-related events in plant genomes. Cytogenet Genome Res. 2008;120:351-7.

13. Mayr B, Kalat M, Ràb P. Localization of NORs and counterstain enhanced fluorescence studies in Perca fluviatilis (Pisces, Percidae). Genetica. 1985;67:51-6.

14. Phillips RB, Hartley SE. Fluorescent banding patterns of the chromosomes of the genus Salmo. Genome. 1988;30:193-7.

15. Sola L, Rossi AR, Laselli V, Rash EM, Monaco PJ. Cytogenetics of bisexual/ unisexual species of Poecilia. II. Analysis of heterochromatin and nucleolar organizer regions in Poecilia mexicana mexicana by C-banding and DAPI, quinacrine, chromomycin A3 and silver staining. Cytogenet Cell Genet. 1992;60:229-35.

16. Rábová M, Ráb P, Ozouf-Costaz C, Ene C, Wanzeböck J. Comparative cytogenetics and chromosomal characteristics of ribosomal DNA in the fish genus Vimba (Cyprinidae). Genetica. 2003;118:83-91.

17. Bellafronte E, Vicari MR, Artoni RF, Margarido VP, Moreira-Filho O. Differentiated ZZ/ZW sex chromosomes in Apareiodon ibitiensis (Teleostei, Parodontidae): considerations on cytotaxonomy and biogeography. J Fish Biol. 2009;75:2313-25.

18. Mandrioli M, Manicardi GC, Machella N, Caputo V. Molecular and cytogenetic analysis of the goby Gobius niger (Teleostei, Gobiidae). Genetica. 2001;110:73-8.

19. Souza IL, Galián J, De La Rúa P, Bertollo LAC, Moreira FO. Non-random distribution of the GC-rich heterochromatin and nucleolar rDNA sites on Astyanax scabripinnis chromosomes. Cytologia. 2001;66:85-91.

20. Volff JN. Genome evolution and biodiversity in teleost fish. Heredity. 2005;94:280-94.

21. Costa AC, Loh SH, Martins LM. Drosophila Trap1 protects against mitochondrial dysfunction in a PINK1/parkin model of Parkinson's disease. Cell Death Dis. 2013;4:e467.

22. Cioffi MB, Martins C, Bertollo LAC. Chromosome spreading of associated transposable elements and ribosomal DNA in the fish Erythrinus erythrinus. Implications for genome change and karyoevolution in fish. BMC Evol Biol. 2010;10:271

23. Martins NF, Bertollo LAC, Troy WP, Feldberg E, Valentin FCS, Cioffi MB. Differentiation and evolutionary relationships in Erythrinus erythrinus (Characiformes, Erythrinidae): comparative chromosome mapping of repetitive sequences. Rev Fish Biol Fisher. 2013;23:261-9.

24. Tautz D, Renz M. Simple sequences are ubiquitous repetitive components of eukaryote genomes. Nucleic Acids Res. 1984;12:4127-38.

25. Cioffi MB, Bertollo LAC. Chromosomal distribution and evolution of repetitive DNAs in fish. In: Garrido-Ramos MA, editor. Genome Dynamics. Basel: Karger; 2012. p. 197-221.

26. Vanzela ALL, Swarça AC, Dias AL, Stolf R, Ruas PM, Ruas CF. Differential distribution of (GA) $9+C$ microsatellite on chromosomes of some animal and plant species. Cytologia. 2002;67:9-13.

27. Cioffi MB, Kejnovsky E, Bertollo LAC. The chromosomal distribution of microsatellite repeats in the wolf fish genome Hoplias malabaricus, focusing on the sex chromosomes. Cytogenet Genome Res. 2011;132:289-96.

28. Yano CF, Poltronieri J, Bertollo LAC, Artoni RF, Liehr T, Cioffi MB. Chromosomal mapping of repetitive DNAs in Triportheus trifurcatus (Characidae, Characiformes): Insights into the differentiation of the Z and W chromosomes. PLoS One. 2014;9, e90946.

29. Wichman HA, Payne CT, Ryder OA, Hamilton MJ, Maltbie M, Baker RJ. Genomic distribution of heterochromatin sequences in equids: implications to rapid chromosomal evolution. J Hered. 1991;82:369-77.

30. López-Flores I, Garrido-Ramos MA. The repetitive DNA content of eukaryotic genomes. In: Garrido-Ramos MA, editor. Genome Dynamics. Basel: Karger; 2012. p. 1-28
31. Bhargava A, Fuentes FF. Mutational dynamics of microsatellites. Mol Biotechnol. 2010;44(3):250-66.

32. Martins C. Chromosomes and repetitive DNAs: a contribution to the knowledge of the fish genome. In: Pizano E, Ozouf-Costaz C, Foresti F, Kapoor BG, editors. Fish Cytogenetics. Enfield: Science Publishers; 2007. p. 421-52.

33. Cioffi MB, Martins C, Bertollo LAC. Comparative chromosome mapping of repetitive sequences. Implications for genomic evolution in the fish, Hoplias malabaricus. BMC Genet. 2009;10:34.

34. Marques DF, Dos Santos FA, Da Silva SS, Sampaio I, Rodrigues LRR. Cytogenetic and DNA barcoding reveals high divergence within the trahira, Hoplias malabaricus (Characiformes: Erythrinidae) from the lower Amazon River. Neotrop Ichthyol. 2013;11(2):459-66.

35. Cioffi MB, Martins C, Centofante L, Jacobina U, Bertollo LAC. Chromosomal variability among allopatric populations of Erythrinidae fish Hoplias malabaricus: Mapping of three classes of repetitive DNAs. Cytogenet Genome Res. 2009;125:132-41.

36. Wainwright PC, Reilly SM. Ecological morphology: integrative organismal biology. Chicago: University of Chicago Press; 1994.

37. Rabosky DL, Santini F, Eastman J, Smith SA, Sidlauskas B, Chang J. Rates of speciation and morphological evolution are correlated across the largest vertebrate radiation. Nat Commun. 2013;4:1958.

38. Wilson AC, Bush GL, Case SM, King MC. Social structuring of mammalian populations and rate of chromosomal evolution. Proc Natl Acad Sci U S A. 1975;72:5061-5.

39. Bush GL, Case SM, Wilson AC, Patton JL. Rapid speciation and chromosomal evolution in mammals. Proc Natl Acad Sci U S A. 1977;74:3942-6.

40. Bush GL. Modes of animal speciation. Ann Rev Eco Syst. 1975;6:339-64.

41. Gibson LJ. Chromosomal changes in mammalian speciation: a literature review. Origins. 1984;11:67-89.

42. Radinsky LB. New Pantodonta and Dinocerata from the Upper Paleocene of Western Colorado. Field Mus Nat Hist Geol. 1966;6:351-84.

43. Prothero DR, Schoch RM. Classification of the Perissodactyla. In: Prothero DR, Schoch RM, editors. The evolution of perissodactyls. New York: Oxford University Press; 1989. p. 530-7.

44. Phillips R, Rab P. Chromosome Evolution in the Salmonidae (Pisces): an update. Biol Rev Camb Philos Soc. 2001;76:1-25.

45. Pellestor F, Anahory T, Lefort G, Puechberty J, Liehr T, Hédon B. Complex chromosomal rearrangements: origin and meiotic behavior. Hum Reprod Update. 2011;17(4):476-94.

46. Butlin RK. Recombination and speciation. Mol Ecol. 2005;14:2621-35.

47. Bertollo LAC, Moreira-Filho O, Galetti Jr PM. Cytogenetics and taxonomy: consideration based on chromosome studies of freshwater fish. J Fish Biol. 1986;28:153-9.

48. Oliveira C, Almeida-Toledo LF, Foresti F, Britski H, Toledo-Filho SA. Chromosome formulae of Neotropical freshwater fishes. Braz J Genet. 1988;11:577-624

49. Rishi KK, Haobam MS. A chromosomal study on four species of snakeheads (Ophiocephalidae: Pisces) with comments on their karyotypic evolution. Caryologia. 1990;43:163-7.

50. Naorem S, Bhagirath T. Chromosomal differentiations in the evolution of channid fishes - molecular genetic perspective. Caryologia. 2006;59:235-40

51. Cioffi MB, Bertollo LAC, Villa MA, Oliveira EA, Tanomtong A, Yano CF. Genomic organization of repetitive DNA elements and its implications for the chromosomal evolution of channid fishes (Actinopterygii, Perciformes). PLoS One. 2015;10(6):e0130199. doi:10.1371/journal.pone.0130199.

52. Gileva EA. A contrasted pattern of chromosome evolution in two genera of lemmings, Lemmus and Dicrostonyx. Genetica. 1983;60:173-9.

53. Ruiz-Herrera A, Castresana J, Robinson TJ. Is mammalian chromosomal evolution driven by regions of genome fragility? Genome Biol. 2006;7:R115.

54. Eldridge MDB, Johnston PG. Chromosomal rearrangements in rock wallabies, Petrogale (Marsupialia: Macropodidae). VIII. An investigation of the non-random nature of karyotypic change. Genome. 1993;36:524-34.

55. Mudry M, Fundia A, Hick A, Gorostiaga MA. Labilidad cromosómica: una posible explicación en el origen de los reordenamientos cromosómicos en cébidos. Bol Primatol Lat. 1995;5:7-15.

56. Duarte JMB, Jorge W. Chromosomal polymorphism in several populations of deer (genus Mazama) from Brazil. Arch Zootec. 1996;45:281-7.

57. Howell WM, Black DA. Controlled silver staining of nucleolus organizer regions with a protective colloidal developer: a 1-step method. Experientia. 1980;36:1014-5. 
58. Sumner AT. A simple technique for demonstrating centromeric heterochromatin. Exp Cell Res. 1972;75:304-6.

59. Martins C, Ferreira IA, Oliveira C, Foresti F, Galetti Jr PM. A tandemly repetitive centromeric DNA sequence of the fish Hoplias malabaricus (Characiformes: Erythrinidae) is derived from 5S rDNA. Genetica. 2006;127:133-14.

60. Kubat Z, Hobza R, Vyskot B, Kejnovsky E. Microsatellite accumulation in the Y chromosome of Silene latifolia. Genome. 2008;51:350-6.

61. Levan A, Fredgra K, Sandberg AA. Nomenclature for centromeric position on chromosomes. Hereditas. 1964:52:201-20.

\section{Submit your next manuscript to BioMed Central} and take full advantage of:

- Convenient online submission

- Thorough peer review

- No space constraints or color figure charges

- Immediate publication on acceptance

- Inclusion in PubMed, CAS, Scopus and Google Scholar

- Research which is freely available for redistribution 